\title{
The thermal effect in Direct Carbon Solid Oxide Fuel Cells
}

Haoran Xu ${ }^{1}$, Bin Chen ${ }^{1}$, Houcheng Zhang ${ }^{1,2}$, Wei Kong ${ }^{1,3}$, Bo Liang ${ }^{4}$, Meng Ni ${ }^{1, *}$

${ }^{1}$ Building Energy Research Group, Department of Building and Real Estate

The Hong Kong Polytechnic University, Hung Hom, Kowloon, Hong Kong, China

${ }^{2}$ Department of Microelectronic Science and Engineering, Ningbo University, Ningbo 315211, China

${ }^{3}$ School of Energy and Power Engineering, Jiangsu University of Science and Technology, Zhenjiang, 212003, China

${ }^{4}$ School of Materials and Energy, Guangdong University of Technology, Guangzhou, 510006, China

\section{Abstract:}

In this paper, the thermal effect in a tubular direct carbon solid oxide fuel cell (DC-SOFC) is studied with a numerical model. After model validation, parametric simulations are carried out to study the effects of operating and structural parameters on the thermal behaviors of DC-SOFCs. It is found that the thermal behaviours of DC-SOFC greatly depends on operating parameters and the temperature field in DC-SOFC is highly non-uniform. The position of peak temperature in the cell is highly dependent on the operating potential. In addition, a smaller distance between the carbon bed and the anode is beneficial for improving the temperature uniformity in the DC-SOFC. The breakdown of heat generation/consumption in DC-SOFC shows that the anode processes contribute the most to the temperature variation in the cell. The results of this study form a solid foundation for better thermal management of DC-SOFC.

Keywords: Solid oxide fuel cell (SOFC); Temperature; Mathematical modeling; Direct carbon fuel cell (DCFC)

* Corresponding author:

Email: bsmengni@polyu.edu.hk; Tel: 852-27664152; Fax: 852-27645131. 


\section{Introduction}

Solid carbon can be obtained easily from fossil fuels or cheap and renewable biomasses such as wood and leaves. Solid carbon fuels are usually used for power generation by conventional heat engines which will emit significant amount of various pollutants (i.e. $\mathrm{SO}_{\mathrm{x}}, \mathrm{CO}_{2}$, and $\mathrm{NO}_{\mathrm{x}}$ ) as byproduct $[1,2]$. Besides, the efficiency of conventional thermal power plant is typically below $40 \%$ or even about $30 \%$ if carbon capture and storage is adopted to reduce the pollutant emission [3]. Although relatively new gas fired CCGT thermal power plant and coal fired power plant have reached an efficiency of 55\% and 40\%, respectively[4], more efficient and environmental friendly strategy using solid carbon fuel for power generation is still of practical importance as solid carbon will be used for energy conversion for a long time.

Solid oxide fuel cell (SOFC) is an advanced energy conversion device converting the fuel into electricity through electrochemical reaction with a high efficiency $(50-60 \%)[5,6]$. An SOFC has an all solid-state structure with a dense electrolyte placed between the porous anode and cathode. In SOFCs, the fuel and oxygen are separated by the oxygen-ion-conducting membrane, resulting in easy pollutant control. The high temperature of SOFCs (i.e. $800^{\circ} \mathrm{C}$ ) facilitates the electrochemical reaction kinetics and low cost catalyst (i.e. Nickel) can be used. SOFCs are fuel flexible. Various alternative fuels, such as $\mathrm{H}_{2}$, various hydrocarbons, $\mathrm{NH}_{3}$ and even solid carbon can be used in SOFC for electricity generation $[7,8]$.

The direct use of solid carbon as a fuel in SOFCs offers a new strategy for efficient power generation with low environmental impact. The direct-carbon solid oxide fuel cell (DC-SOFC) has received extensive research since Nakagawa and Ishida[9] first prepared and 
tested DC-SOFCs. They also proposed the " $\mathrm{CO}_{2}$ shuttling theory" as the working mechanisms of DCFC. It's proposed that the reaction between carbon and $\mathrm{CO}_{2}$ produces $\mathrm{CO}$, which is electrochemically oxidized at the DCFC anode. Lee et al. [10] performed system exergy analyses of DC-SOFCs and found that the DC-SOFCs were more efficient than a carbon fueled SOFC system with separate carbon gasification unit and SOFC unit. They achieved a power density of $220 \mathrm{~mW} \mathrm{~cm}^{-2}$ at $0.68 \mathrm{~V}$ at $1178 \mathrm{~K}$.

Since CO is participated in the electrochemical reaction, enhancing the Boudouard reaction between the $\mathrm{CO}_{2}$ and carbon is effective in improving the performance of DC-SOFCs. The Boudouard reaction rate could be increased by increasing the operating temperature or using suitable catalyst to facilitate the reaction. However, increasing the temperature could decrease the lifetime of the DC-SOFC thus it is critical to develop suitable catalyst for Boudouard reaction at reduced temperature. Wu et al.[11] adopted $\mathrm{Fe}_{\mathrm{m}} \mathrm{O}_{\mathrm{n}}-\mathrm{M}_{\mathrm{x}} \mathrm{O}(\mathrm{M}=\mathrm{Li}, \mathrm{K}, \mathrm{Ca})$ as catalyst to enhance the Boudouard reaction in SOFC anode and the peak power density was $297 \mathrm{~mW} \mathrm{~cm}^{-2}$ at $1123 \mathrm{~K}$. Li et al.[12] and Tang et al.[13] also found that by introducing appropriate catalyst (such as Fe-based) into DC-SOFC, the operating temperature could be decreased and the performance could be improved. Bai et al. [14] studied a 3-cell DC-SOFC stack and obtained a power density of $465 \mathrm{~mW} \mathrm{~cm}^{-2}$ at $1123 \mathrm{~K}$. They also found that the life time of the DC-SOFC and the carbon fuel utilization were both decreased with increasing current.

In addition to power generation, new DC-SOFC systems have been proposed and demonstrated to be feasible for simultaneous power and gas cogeneration. Alexander et al. $[15,16]$ developed a steam-carbon fuel cell for simultaneous generation of $\mathrm{H}_{2}$ and power and 
the efficiency was over $78 \%$. Xie et al. $[1,17]$ verified the $\mathrm{CO}_{2}$ shuttling mechanism of DC-SOFCs by comparing the electrochemical characteristics of a CO-fueled SOFC with a DC-SOFC. They also proposed CO gas and electrical power co-generation by a DC-SOFC, which significantly increased the overall efficiency of the DC-SOFC.

A few groups also studied the practical applications of DC-SOFCs. Zhou et al.[18] fabricated a cathode supported tubular DC-SOFC with a continuous fuel supply to the anode. They proposed that the DC-SOFC performance could depend on the distance between the porous anode layer and the carbon bed, which was verified by our previous isothermal modeling work [19]. Jiao et al.[20] used structurally modified coal char as fuel in a DC-SOFC and found that the Boudouard reaction activity was greatly improved, which consequently improved the power output of the cell. In addition to $\mathrm{CO}_{2}, \mathrm{H}_{2} \mathrm{O}$ can also be used as a gasifying agent to convert solid carbon into gaseous CO. Lee et al.[10] compared the thermodynamic performance of DC-SOFC with $\mathrm{H}_{2} \mathrm{O}$ gasification and $\mathrm{CO}_{2}$ gasification and no significant difference in terms of electrical output was found. However, Ong and Ghoniem[21] developed a 1D MEA model and found that significant performance improvement could be achieved through recycling $\mathrm{H}_{2} \mathrm{O}$ rather than $\mathrm{CO}_{2}$ between anode and the gasifier in an indirect DCFC.

The above-mentioned studies demonstrated great potential of DC-SOFC and attempted to understand the fundamental mechanisms in DC-SOFC. However, it can also be seen that the understanding on the DC-SOFC is still limited, due to the highly coupled chemical/chemical reactions, heat transfer and complex gas transport process in the porous media. For example, there is no detailed thermal analysis of DC-SOFCs in the current 
literatures. Considering that the temperature distribution in DC-SOFCs not only affects the chemical reaction and electrochemical reaction of the cells, but also affects the life time of DC-SOFCs due to the heat management and thermal stress. In the previous study by the same research group [19], a mathematical model is developed for DC-SOFC but the uniform temperature field is assumed and the thermal effect is completely neglected. In this paper, the model developed in the previous study is extended to study the thermal effects on the DC-SOFC temperature distribution which is the new contribution of this paper.

\section{Model development}

\subsection{Assumptions and computational domain}

A 2D model including the electrochemical reactions in both electrode, Boudouard reaction at the anode side, ion/electron transport, mass/momentum transport as well as heat transfer is developed for a tubular DC-SOFC. This model is an extension from our previous work[19] which has been well validated. Compared with our previous work, cell length in this model has been extended from $9 \mathrm{~mm}$ to $90 \mathrm{~mm}$, and thermal effect has also been considered to investigate the cell temperature distribution.

The various processes in a tubular DC-SOFC are shown in Fig. 1(a). Solid carbon is placed at the anode side with a given distance from the porous anode and air is continuously supplied to the cathode. Initial $\mathrm{CO} / \mathrm{CO}_{2}$ comes from the reactions between carbon fuel and initial $\mathrm{O}_{2}$ in the anode chamber. $\mathrm{CO}$ molecules produced in anode chamber diffuse to the reaction sites in the porous anode where they react with $\mathrm{O}^{2-}$ through electrochemical reaction at TPB sites. By the electrochemical reaction, $\mathrm{CO}_{2}$ molecules are then formed and electrons 
are released. After that, the produced $\mathrm{CO}_{2}$ molecules in anode diffuse back to the chamber to gasify solid carbon into $\mathrm{CO}$ molecules through the Boudouard reaction. These processes take place continuously between the porous anode and the anode chamber to maintain $\mathrm{CO} / \mathrm{CO}_{2}$ cycling while generating electricity, related formulas are shown in Eqs. (1-5).

The following assumptions are adopted in the present study.

(1) The electrochemical reactions occur on triple phase boundaries (TPBs). The electronic/ionic conducting phases are respectively continuous and homogeneous.

(2) All gases $\left(\mathrm{CO}, \mathrm{CO}_{2}, \mathrm{O}_{2}\right.$ and $\left.\mathrm{N}_{2}\right)$ behave like ideal gases. The gas flow in the gas channel is laminar and incompressible.

(3) The DC-SOFC is in a steady state operation: the amount of carbon in the carbon chamber is considered to be constant.

(4) Thermal radiation is assumed to be negligible.

\subsection{The model}

This 2D numerical model considers the reaction processes (electrochemical and chemical), transport of electrons/ions, transport of mass and momentum and heat transfer. The following modules are included in the numerical model: chemical model, electrochemical model, mass transfer model, fluid mechanics model and heat transfer model.

\subsubsection{Chemical model}

Unlike gaseous fuel-fed SOFCs, solid carbon is used as the fuel for DC-SOFCs. Although 
$\mathrm{CO}$ is the real material that participates in electrochemical reaction which happens in anode. It is solid carbon that offers chemical energy, and $\mathrm{CO}$ is the intermediate that transports chemical energy from solid carbon to anode. Thus the chemical reaction (Boudouard reaction) is a key process in this system. The Boudouard reaction is described as shown in reaction (1)

$$
\mathrm{C}+\mathrm{CO}_{2} \leftrightarrow 2 \mathrm{CO}
$$

The Boudouard reaction rate $\left(R_{r b}\right)$ can be calculated as shown in Eq. (2) [22]:

$$
R_{r b}=k_{r b} \exp \left(-E_{r b} / R T\right) c_{C O_{2}}
$$

\subsubsection{Electrochemical model}

The electrochemical model is used to determine the current density (related to electrochemical reaction rate) at specified operating conditions. As shown in Fig. 1(a), $\mathrm{CO} / \mathrm{CO}_{2}$ mixture flows in the anode and air flows in the cathode. $\mathrm{O}_{2}$ molecules diffuse from the cathode channel to the TPB in the porous cathode, where they react with electrons to form $\mathrm{O}^{2-}$ through reactions (3).

$$
O_{2}+4 e^{-} \rightarrow 2 O^{2-}
$$

The $\mathrm{O}^{2-}$ subsequently conduct to the anode through the dense electrolyte. At the TPB of the anode, the oxygen ions oxidize $\mathrm{CO}$ to form $\mathrm{CO}_{2}$ and release electrons as shown in reaction (4):

$$
2 \mathrm{CO}+2 \mathrm{O}^{2-} \rightarrow 2 \mathrm{CO}_{2}+4 e^{-}
$$

As $\mathrm{CO}$ is the actual material that participate in the electrochemical reaction instead of solid 
carbon in DC-SOFC. By combining Eq. (3) and Eq. (4), the overall electrochemical reaction can be written as Eq. (5):

$$
2 \mathrm{CO}+\mathrm{O}_{2} \rightarrow 2 \mathrm{CO}_{2}
$$

Related operating potential can be determined by its thermodynamic equilibrium potential and operating overpotential losses as shown in Eq. (6):

$$
V=E_{e q}-\eta_{a c t, a n}-\eta_{a c t, c a}-\eta_{\text {ohmic }}
$$

Here $E_{e q}$ is the equilibrium potential (Nernst potential) of the overall electrochemical reaction which is determined by the thermodynamic property of the reaction. $\eta_{\text {act }}$ is the activation polarization (also called overpotential). $\eta_{\text {ohmic }}$ is the ohmic loss from the conduction of ions and electrons. The concentration losses due to gas diffusion are not included in Eq. (6) as local partial pressures of gas species at the TPBs are used in calculating the equilibrium potential.

\subsubsection{Open-circuit voltage}

As CO participates in the electrochemical reaction in DC-SOFCs, the open-circuit voltage (OCV, also called equilibrium potential) for reaction (5) can be calculated by Eq. (7):

$$
E_{C O}=E_{C O}^{0}+\frac{R T}{2 F} \ln \left[\frac{P_{C O}^{L}\left(P_{O_{2}}^{L}\right)^{1 / 2}}{P_{C O_{2}}^{L}}\right]
$$

$E^{0}$ is the potential under standard conditions, $\mathrm{R}$ is the universal gas constant $\left(8.3145 \mathrm{~J} \mathrm{~mol}^{-1}\right.$ $\left.\mathrm{K}^{-1}\right) . \quad \mathrm{F}$ is the Faraday constant $\left(96485 \mathrm{C} \mathrm{mol}^{-1}\right) . \quad \mathrm{T}$ is the operating temperature $(\mathrm{K}) . P_{C O}^{L}$, $P_{\mathrm{CO}_{2}}^{L}$ and $P_{\mathrm{O}_{2}}^{L}$ respectively represent the local partial pressures of $\mathrm{CO}, \mathrm{CO}_{2}$ and $\mathrm{O}_{2}$. The value of $E_{C O}^{0}$ can be calculated by Eq. (8)[23]: 


$$
E_{C O}^{0}=1.46713-0.0004527 T
$$

Therefore, the OCV of DC-SOFC can be calculated as shown in Eq. (9) by combining Eq. (7) and Eq. (8).

$$
E_{c o}=1.46713-0.0004527 T+\frac{R T}{2 F} \ln \left[\frac{P_{C O}^{L}\left(P_{O_{2}}^{L}\right)^{1 / 2}}{P_{C O_{2}}^{L}}\right]
$$

\subsubsection{Activation polarization}

Activation polarization is the potential loss related to the electrochemical reaction kinetics.

Butler-Volmer equation is used to determine the activation loss at a given current density [24].

$$
i=i_{0}\left\{\exp \left(\frac{\alpha n F \eta_{a c t}}{R T}\right)-\exp \left(\frac{(1-\alpha) n F \eta_{\text {act }}}{R T}\right)\right\}
$$

Here $i_{0}$ is the exchange current density. $\quad \alpha$ is the transfer coefficient and $\mathrm{n}$ is the number of electrons involved in a single electrochemical reaction.

\subsubsection{Ohmic overpotential loss}

The ohmic loss in the DC-SOFC results from conductions of ions and electrons. Thus it is largely dependent on the ionic/electronic conductivity of electrode and electrolyte. The ohmic loss in the electrolyte and electrode can be determined by Eq. (11) and Eq. (12):

$$
\begin{aligned}
& i_{l}=-\sigma_{l}^{e f f} \nabla\left(\emptyset_{l}\right) \\
& i_{s}=-\sigma_{\text {s.eff }} \nabla\left(\emptyset_{s}\right)
\end{aligned}
$$

Here $\sigma_{l . e f f}$ and $\sigma_{\text {s.eff }}$ are the effective conductivities for ions and electrons, respectively. 
$\emptyset_{l}$ is the potential of the ionic-conducting phase. $\emptyset_{s}$ is the potential of the electronic-conducting phase. In the porous anode and cathode, $\sigma_{\text {l.eff }}$ and $\sigma_{\text {s.eff }}$ are dependent on the microstructures of the electrodes such as tortuosity and volume fraction as shown in Eq. (13) and Eq. (14).

$$
\begin{aligned}
& \sigma_{l}^{e f f}=\sigma_{l} \cdot \frac{V_{l}}{\tau_{l}} \\
& \sigma_{s}^{e f f}=\sigma_{s} \cdot \frac{V_{s}}{\tau_{s}}
\end{aligned}
$$

Here $\sigma_{l}$ and $\sigma_{s}$ are the intrinsic conductivities for ions and electrons. $V_{l}$ and $V_{s}$ are the volume fraction values in ionic and electronic phases, $\tau_{l}$ and $\tau_{s}$ are the tortuosity value in ionic and electronic phases.

\subsubsection{Mass transport}

In the porous anode and cathode, both Knudsen diffusion and free molecular diffusion are considered. While in the gas channels, the Knudsen diffusion is insignificant and thus not considered. The general Fick's model is used to simulate the mass transport in the channel and porous electrodes as shown in Eq. (15):

$$
N_{i}=-\frac{1}{R T}\left(\frac{B_{0} y_{i} P}{\mu} \frac{\partial \mathrm{P}}{\partial \mathrm{z}}-D_{i}^{e f f} \frac{\partial\left(y_{i} \mathrm{P}\right)}{\partial \mathrm{z}}\right)(i=1, \ldots, n)
$$

Where $N_{i}$ is the flux of gas species, $B_{0}$ is the permeability of the porous electrodes, $y_{i}$ is the mole fraction of component $\mathrm{i}, \mu$ is the gas viscosity and $D_{i}^{\text {eff }}$ is the effective diffusion coefficient of species $i$., which can be determined using both Knudsen diffusion coefficient $\left(D_{i k}^{e f f}\right)$ and molecular diffusion coefficient $\left(D_{i m}^{\text {eff }}\right)$ and as Eq. (16): 


$$
D_{i}^{e f f}=\frac{\varepsilon}{\tau}\left(\frac{1}{D_{i m}^{e f f}}+\frac{1}{D_{i k}^{e f f}}\right)^{-1}
$$

Here $\varepsilon$ is the volume fraction of the pores, $\tau$ is the tortuosity factor. $D_{i m}^{e f f}$ and $D_{i k}^{e f f}$ are related to the electrode structure and the operating conditions. Details of on the calculation of $D_{i k}^{e f f}$ and $D_{i m}^{e f f}$ can be found in reference [25-27].

\subsubsection{Fluid flow model}

The momentum conservation is described by the Navier-Stokes (N-S) equation. For the gas channels, the momentum conservation can be written as Eq. (17):

$$
\rho \frac{\partial u}{\partial t}+\rho u \nabla u=-\nabla p+\nabla\left[\mu\left(\nabla u+(\nabla u)^{T}\right)-\frac{2}{3} \mu \nabla u\right]
$$

For the anode chamber (with porous carbon bed) and the porous electrodes, the modified N-S equation including the Darcy's term is used:

$$
\rho \frac{\partial u}{\partial t}+\rho u \nabla u=-\nabla p+\nabla\left[\mu\left(\nabla u+(\nabla u)^{T}\right)-\frac{2}{3} \mu \nabla u\right]-\frac{\varepsilon \mu u}{k}
$$

Here $\rho$ is the gas density, $\mathrm{u}$ is the velocity vector, $\mathrm{p}$ is pressure and $\varepsilon$ is the porosity of the electrode.

\subsubsection{Heat transfer model}

In DC-SOFCs, electrochemical reactions in TPB sites generates heat while the chemical reaction (Boudouard reaction) in anode chamber consumes heat. This will not only result in the gradient of temperature along the cell length, but also along the cell width. General heat balance equation is used to simulate the heat transfer process in DC-SOFC as: 


$$
\rho C_{p} u \cdot \nabla T+\nabla \cdot\left(-\lambda_{e f f} \nabla T\right)=Q
$$

where $C_{p}$ is the heat capacity of fluid, $\mathrm{u}$ is the fluid velocity field, $\lambda_{e f f}$ is the effective heat conductivity and $\mathrm{Q}$ is the heat source term representing the heat consumption or generation due to chemical/electrochemical reactions and various overpotential losses. In the porous structure of electrodes, $\lambda_{\text {eff }}$ can be calculated as:

$$
\lambda_{e f f}=(1-\varepsilon) \lambda_{s}+\varepsilon \lambda_{l}
$$

where $\lambda_{s}$ and $\lambda_{l}$ are heat conductivity of solid and liquid phase, respectively. Value of above material property parameters are listed in Table 1.

\subsection{Model solution}

The potentials are specified at the outer boundaries of the two electrodes. The bottom and top of the DC-SOFC is electrically insulated. An inflow gas mole fraction is given at the cathode inlet. The outflow condition is specified at the outlets of the gas channels. Zero flux is specified at the end of anode chamber (carbon bed) and the end of the porous electrodes. Gas flow rate (SCCM) is specified at the inlet of cathode gas channel while pressure condition is specified at the outlets of the two gas channels. The outer boundary of cathode chamber, the end of anode chamber, electrodes and electrolyte are thermally insulated. Gas temperature is specified at the cathode inlet.

The values of input parameters and tuning parameters are summarized in Table 1 and Table 2. Details can be found in our previous work[19]. The parameters are purposely varied to investigate how they influence the performance of DC-SOFC. The operating parameters are listed in Table 3 to Table 5. 
The model is solved at given operating conditions, such as the operating potential, the gas flow rate, and the inlet gas temperature. The output of the model is mainly the temperature distribution and the electrochemical characteristics of the DC-SOFC. The commercial software COMSOL MULTIPHYSICS ${ }^{\circledR}$ is employed for the numerical simulation.

This model is an extension of our previous model, which has already been validated with experimental data from the literature (Fig. 1(b)). More detailed information about the model validation can be found in [19].

\section{Results and discussion}

\subsection{Effect of applied voltage}

The relationship between operating potential, current density and average electrolyte temperature at given operating conditions are shown in Fig. 2. The detailed operating conditions are listed in Table 3.

As can be seen in Fig. 2, when operating potential decreases from $1.0 \mathrm{~V}$ to $0.6 \mathrm{~V}$, the cell current density is found to increase from $754 \mathrm{~A} \mathrm{~m}^{-2}$ to $5417 \mathrm{~A} \mathrm{~m}^{-2}$. The average electrolyte temperature decreases slightly when the operating potential decreases from $1035 \mathrm{~K}$ at $1.0 \mathrm{~V}$ to $1029 \mathrm{~K}$ at $0.9 \mathrm{~V}$ and increases quickly to $1104 \mathrm{~K}$ at $0.6 \mathrm{~V}$. The electrochemical reaction rate and overpotential losses both increase with decreasing operating potential, which in turn leads to more heat generation. However, more $\mathrm{CO}_{2}$ can be generated at a higher current density, which increases the rate of the endothermic Boudouard reaction and more heat consumption in the anode chamber. These combined effects result in the slightly 
temperature decrease when operating potential decreases from $1.0 \mathrm{~V}$ to $0.9 \mathrm{~V}$. With a further decrease of operating potential from $0.9 \mathrm{~V}$ to $0.6 \mathrm{~V}$, the temperature of DC-SOFC is increased substantially, indicating that the heat generation from the electrochemical reactions and overpotential losses is higher than heat consumption by Boudouard reaction.

The temperature distribution of the DC-SOFC is shown in Fig. 3(a). At an operating potential of $1.0 \mathrm{~V}$, the temperature decreases along the DC-SOFC length and the peak temperature occurs at the cathode inlet. While at an operating potential of $0.6 \mathrm{~V}$, the temperature increases along the cell length and the peak temperature occurs at the cathode outlet. The different temperature distribution patterns are caused by the electrochemical and chemical processes in the DC-SOFC. At a high operating potential, the heat generation from electrochemical reaction and overpotential losses is lower than heat consumption by endothermic Boudouard reaction, leading to a decrease of cell temperature. While at a relatively lower operating potential, exothermic processes are greatly enhanced due to increased current density, which in turn increase the temperature of DC-SOFC.

The temperature of the anode temperature is found to be always lower than the cathode temperature at the same cell length position, as endothermic Boudouard reaction takes place in the anode chamber. It is important to point out that the temperature distribution of the DC-SOFC is almost uniform at an operating potential of about $0.65 \mathrm{~V}$. For long-term and stable operation DC-SOFC, the uniform temperature distribution is desirable to reduce the thermal stress in the cell. The results of the present study clearly demonstrate that the temperature uniformity of DC-SOFC can be achieved by controlling the operating conditions. It is also found from Fig. 3(b) that the gauge pressure in the anode chamber could be 
relatively high since one end of the anode is sealed.

Fig. 4 (a). shows a breakdown on heat generation/consumption from different components in the cell. It can be seen that the porous anode and the anode chamber contribute most to the heat generation and consumption, respectively. At an operating potential of $1.0 \mathrm{~V}$, the heat consumption by Boudouard reaction in the anode chamber is slightly higher than the heat generation from electrochemical reaction and overpotential losses, which well explains the thermal effect in Figure 3 (a). In the porous anode, the entropy change due to electrochemical reaction contributes to over $90 \%$ of heat generation in the anode while activation loss in anode contributes to about $9.85 \%$. At an operating potential of 0.6 , both the heat generation and heat consumption are substantially enhanced and the heat generation from electrolyte and the cathode are not negligible. The total heat generation is found to be higher than the heat consumption, again in consistence with the results in Figure 3 (a). Compared with the $1 \mathrm{~V}$ case, the anode activation loss contributes to about $29 \%$ of the total heat generation in the anode at $0.6 \mathrm{~V}$. The results suggest that the heat generation/consumption in the anode is the key for controlling the temperature field of DC-SOFC. Thus it is possible to adjust the operating parameters to control the chemical and electrochemical processes in the anode to control the temperature distribution in DC-SOFC. It can also be found from Fig. 4(b) that the anode electrochemical reaction rate is much higher in the narrow region near the electrolyte/anode interface, which means anode activation polarization heat is most generated in this narrow region.

\subsection{Effect of cathode inlet gas temperature}

Inlet gas temperature will also affect the temperature distribution in the cell. Detailed 
operating parameters are listed in Table 4.

As shown in Fig. 5, at a potential of $1 \mathrm{~V}$, cell temperature decreases from inlet to outlet along the cell length at cathode inlet gas temperature from $1023 \mathrm{~K}$ to $1173 \mathrm{~K}$. It can also be found from Fig. 5 that the temperature gradient along the cell length increases with increasing cathode inlet gas temperature. As shown in Fig. 6(a), when the operating potential is $0.6 \mathrm{~V}$, cell temperature increases from inlet to outlet along the cell length. However, it should also be noted that when cell operates with a relative high cathode inlet gas temperature $(1123 \mathrm{~K})$, the peak temperature could occur at the middle of the DC-SOFC. This is because electrochemical reaction rate is very high at a high temperature and low operating potential and oxygen is almost exhausted in the cathode channel (Fig. 6(b)), resulting in nearly zero electrochemical reaction and no heat generation in the end of the DC-SOFC. For comparison, the rate of endothermic chemical reaction is still high throughout the anode chamber, decreasing the temperature of DC-SOFC in the downstream.

\subsection{Effect of distance between carbon and anode}

Previous study has shown how the distance between carbon fuel and anode (Dce) will affect the performance of DC-SOFC [19]. As the thermal conductivity of gas is much smaller than that of solid carbon, the increase of Dce will surely increase the variation of temperature in the cell. Thus the effect of Dce on the temperature distribution of the cell is discussed, detailed operating parameters are listed in Table 5.

Fig. 7 shows the effects of Dce on the temperature distribution in the cell with $1073 \mathrm{~K}$ cathode 
inlet gas temperature and $0.7 \mathrm{~V}$ operating potential. Distance between carbon and anode surface varies from $59 \mu \mathrm{m}$ to $2059 \mu \mathrm{m}$ in this study. As can be seen from Fig. 7, when Dce is quite small $(59 \mu \mathrm{m})$, the gradient along the cell width is quite small. With the increase of Dce, there occurs an obvious temperature boundary between solid carbon and anode gas channel and the gradient along the cell width becomes quite large.

Besides, it is observed from Fig. 8 that the $\mathrm{CO}$ molar fraction in anode decreases quickly with the increase of Dce, which is due to the increased gas transport difficulty and lower chemical reaction temperature caused by larger Dce. Thus, it is also important to keep a small distance between carbon fuel and anode when cell is placed horizontally.

\section{Conclusions}

A multi-physics model is developed to study the thermal effect in a tubular DC-SOFC. The model fully considers the electrochemical reaction, chemical reactions, transport of ions/electrons, mass transport, momentum transport and heat transfer processes in the DC-SOFC. Parametric simulations are carried out to investigate how the operating potential, cathode inlet gas temperature and distance between the carbon fuel and anode influence the temperature distribution and electrochemical characteristics of DC-SOFC.

It is found that the operating potential has a significant effect on the temperature distribution in DC-SOFC. With the decrease of operating potential, the overall cell temperature increases quickly. Beside, the temperature gradient also changes from negative to positive along the cell length with the cell operating potential decreasing from $1.0 \mathrm{~V}$ to $0.6 \mathrm{~V}$ and a relative even 
temperature distribution of the cell is found when the operating potential is around $0.65 \mathrm{~V}$. It is also observed from the breakdown analysis that most of the heat is generated from anode, where entropy change heat is the majority part compared with other processes.

Cathode inlet gas temperature is also found to play an important role on the temperature distribution of the cell. When the operating voltage is high $(1.0 \mathrm{~V})$, cathode inlet gas plays as the outer heat source and it plays as the outer heat sink when the operating voltage is low $(0.6$ V). It should also be noted that when the cathode inlet gas temperature is high $(1123 \mathrm{~K})$, cathode oxygen may be exhausted in the cell, which not only causes a peak temperature point in the middle position of the cell length but also decreases cell's electrochemical performance.

The effect of distance between carbon fuel and anode on temperature distribution is also studied in this work. It is found that the temperature gradient increases quickly along the cell width with the increase of Dce due to the small thermal conductivity of the gas.

\section{Acknowledgement}

This research is supported by a grant of SFC/RGC Joint Research Scheme (X-PolyU/501/14) from Research Grant Council, University Grants Committee, Hong Kong SAR.

We gratefully acknowledge the financial support of the National Science Foundation of China (Grant No. 51406091 and Grant No. 21406095). 


\section{Nomenclature}

Abbreviation

DC-SOFC

PEN

SCCM

SOFC

TPB

Roman

$B_{0}$

$\mathrm{C}_{\mathrm{CO}_{2}}$

$C_{p}$

$D_{c e}$

$D_{i}^{e f f}$

$D_{i k}^{e f f}$

$D_{\text {im }}^{\text {eff }}$

$E_{a}$

$E_{C O}$

$E_{C O}^{0}$

$E_{e q}$

$E_{r b}$

F

$i_{o}$

$k_{r b}$

$L_{\text {cell }}$

$\mathrm{n}$

$N_{i}$

$p$

$R$

$R_{c e}$

$R_{c e}$

$\mathrm{T}$

u

V

$y_{i}$

Greek letters

$\alpha$
Solid oxide fuel cell direct using carbon as fuel

Positive Electrode-Electrolyte-Negative electrode assembly

Standard cubic centime per minute

Solid oxide fuel cell

Triple phase boundary

Permeability coefficient, $\mathrm{m}^{2}$

Molar concentration of carbon dioxide, $\mathrm{mol} \cdot \mathrm{m}^{-3}$

Heat capacity, $\mathrm{J} \cdot \mathrm{K}^{-1}$

Distance between carbon and anode

Effective diffusivity of species $i, \mathrm{~m}^{2} \cdot \mathrm{s}^{-1}$

Knudsen diffusion coefficient of $i, \mathrm{~m}^{2} \cdot \mathrm{s}^{-1}$

Molecular diffusion coefficient of $i, \mathrm{~m}^{2} \cdot \mathrm{s}^{-1}$

Active energy, $\mathrm{J} \cdot \mathrm{mol}^{-1}$

Equilibrium potential for carbon monoxide oxidization, $\mathrm{V}$

Standard equilibrium potential for carbon monoxide oxidization, $\mathrm{V}$

Equilibrium Nernst potential, V

Active energy of Boudouard reaction, $\mathrm{J} \cdot \mathrm{mol}^{-1}$

Faraday constant, $96485 \mathrm{C} \cdot \mathrm{mol}^{-1}$

Exchange current density, $\mathrm{A} \cdot \mathrm{m}^{-2}$

Equilibrium constant of Boudouard reaction, $\mathrm{s}^{-1}$

Length of the cell, $\mathrm{mm}$

Number of electrons transferred per electrochemical reaction

Flux of mass transport, $\mathrm{kg} \cdot \mathrm{m}^{-3} \cdot \mathrm{s}^{-1}$

(partial) Pressure, Pa

Gas constant, $8.314 \mathrm{~J} \cdot \mathrm{mol}^{-1} \cdot \mathrm{K}^{-1}$

Ratio $D_{c e}$ and cell length

Reaction rate of Boudouard reaction, $\mathrm{mol} \cdot \mathrm{m}^{-3} \cdot \mathrm{s}^{-1}$

Temperature, $\mathrm{K}$

Velocity field, $\mathrm{m}^{3} \cdot \mathrm{s}^{-1}$

Volume fraction

Molar fraction of component $\mathrm{i}$

Charge transfer coefficient 


$\begin{array}{ll}\beta_{\mathrm{H}_{2}} & \text { Electrochemical kinetics parameter for } \mathrm{H}_{2} \\ \varepsilon & \text { Porosity } \\ \eta_{\text {act }, \text { an }} & \text { Anode activation polarization, } \mathrm{V} \\ \eta_{\text {act }, \mathrm{la}} & \text { Cathode activation polarization, } \mathrm{V} \\ \eta_{\text {ohmic }} & \text { Ohmic polarization, } \mathrm{V} \\ \kappa & \text { Permeability, } \mathrm{m}^{2} \\ \lambda & \text { Thermal conductivity, } \mathrm{W} \cdot \mathrm{m}^{-1} \mathrm{~K}^{-1} \\ \mu & \text { Dynamic viscosity of fluid, } \mathrm{Pa} \cdot \mathrm{s} \\ \rho & \text { Fluid density, } \mathrm{kg} \cdot \mathrm{m}^{-3} \\ \sigma & \text { Conductivity, } \mathrm{S} / \mathrm{m} \\ \tau & \text { Tortuosity } \\ \varnothing & \text { Potential, } \mathrm{V}\end{array}$

$\begin{array}{ll}\text { Subscripts } & \\ \text { an } & \text { Anode } \\ \text { ca } & \text { Cathode } \\ \text { co } & \text { Carbon monoxide } \\ 1 & \text { Ionic phase } \\ \text { s } & \text { Electronic phase }\end{array}$

$\begin{array}{ll}\text { Superscripts } & \\ 0 & \text { Parameter at equilibrium conditions } \\ \text { eff } & \text { Effective } \\ \text { L } & \text { Local }\end{array}$

\section{References}

[1] Xie Y, Cai W, Xiao J, Tang Y, Liu J, Liu M. Electrochemical gas-electricity cogeneration through direct carbon solid oxide fuel cells. Journal of Power Sources. 2015;277:1-8.

[2] Liu R, Zhao C, Li J, Zeng F, Wang S, Wen T, et al. A novel direct carbon fuel cell by approach of tubular solid oxide fuel cells. Journal of Power Sources. 2010;195:480-2.

[3] Giddey S, Badwal SPS, Kulkarni A, Munnings C. A comprehensive review of direct carbon fuel cell technology. Progress in Energy and Combustion Science. 2012;38:360-99.

[4] Bianco V, Scarpa F, Tagliafico LA. Long term outlook of primary energy consumption of the Italian thermoelectric sector: Impact of fuel and carbon prices. Energy. 2015;87:153-64.

[5] Ni M. Modeling and parametric simulations of solid oxide fuel cells with methane carbon dioxide reforming. Energy Conversion and Management. 2013;70:116-29.

[6] Zhang H, Chen J, Zhang J. Performance analysis and parametric study of a solid oxide fuel cell fueled by carbon monoxide. International Journal of Hydrogen Energy. 2013;38:16354-64. 
[7] Ni M. Thermo-electrochemical modeling of ammonia-fueled solid oxide fuel cells considering ammonia thermal decomposition in the anode. International Journal of Hydrogen Energy. 2011;36:3153-66.

[8] Ni M, Leung DYC, Leung MKH. Thermodynamic analysis of ammonia fed solid oxide fuel cells: Comparison between proton-conducting electrolyte and oxygen ion-conducting electrolyte. Journal of Power Sources. 2008;183:682-6.

[9] Nakagawa N, Ishida M. Performance of an internal direct-oxidation carbon fuel cell and its evaluation by graphic exergy analysis. Industrial \& Engineering Chemistry Research. 1988;27:1181-5.

[10] Lee AC, Mitchell RE, Gür TM. Thermodynamic analysis of gasification-driven direct carbon fuel cells. Journal of Power Sources. 2009;194:774-85.

[11] Wu Y, Su C, Zhang C, Ran R, Shao Z. A new carbon fuel cell with high power output by integrating with in situ catalytic reverse Boudouard reaction. Electrochemistry Communications. 2009;11:1265-8.

[12] Li C, Shi Y, Cai N. Performance improvement of direct carbon fuel cell by introducing catalytic gasification process. Journal of Power Sources. 2010;195:4660-6.

[13] Tang Y, Liu J. Effect of anode and Boudouard reaction catalysts on the performance of direct carbon solid oxide fuel cells. International Journal of Hydrogen Energy. 2010;35:11188-93.

[14] Bai Y, Liu Y, Tang Y, Xie Y, Liu J. Direct carbon solid oxide Fuel Cell—a potential high performance battery. International Journal of Hydrogen Energy. 2011;36:9189-94.

[15] Alexander BR, Mitchell RE, Gür TM. Steam-Carbon Fuel Cell Concept for Cogeneration of Hydrogen and Electrical Power. Journal of The Electrochemical Society. 2011;158:B505-B13.

[16] Alexander BR, Mitchell RE, Gür TM. Viability of Coupled Steam-Carbon-Air Fuel Cell Concept for Spontaneous Co-Production of Hydrogen and Electrical Power. Journal of The Electrochemical Society. 2012;159:F810-F8.

[17] Xie Y, Tang Y, Liu J. A verification of the reaction mechanism of direct carbon solid oxide fuel cells. Journal of Solid State Electrochemistry. 2012;17:121-7.

[18] Zhou J, Ye XF, Shao L, Zhang XP, Qian JQ, Wang SR. A promising direct carbon fuel cell based on the cathode-supported tubular solid oxide fuel cell technology. Electrochimica Acta. 2012;74:267-70.

[19] Xu H, Chen B, Liu J, Ni M. Modeling of direct carbon solid oxide fuel cell for CO and electricity cogeneration. Applied Energy. 2016;178:353-62.

[20] Jiao Y, Zhao J, An W, Zhang L, Sha Y, Yang G, et al. Structurally modified coal char as a fuel for solid oxide-based carbon fuel cells with improved performance. Journal of Power Sources. 2015;288:106-14.

[21] Ong KM, Ghoniem AF. Modeling of indirect carbon fuel cell systems with steam and dry gasification. Journal of Power Sources. 2016;313:51-64.

[22] Mon E, Amundson NR. Diffusion and Reaction in a Stagnant Boundary Layer about a Carbon Particle. 2. An Extension. Industrial \& Engineering Chemistry Fundamentals. 1978; 17:313-21.

[23] Ni M. Modeling of SOFC running on partially pre-reformed gas mixture. International Journal of Hydrogen Energy. 2012;37:1731-45. 
[24] Kakaç S, Pramuanjaroenkij A, Zhou XY. A review of numerical modeling of solid oxide fuel cells. International Journal of Hydrogen Energy. 2007;32:761-86.

[25] Suwanwarangkul R, Croiset E, Fowler MW, Douglas PL, Entchev E, Douglas MA. Performance comparison of Fick's, dusty-gas and Stefan-Maxwell models to predict the concentration overpotential of a SOFC anode. Journal of Power Sources. 2003;122:9-18.

[26] Todd B, Young JB. Thermodynamic and transport properties of gases for use in solid oxide fuel cell modelling. Journal of Power Sources. 2002;110:186-200.

[27] Chan SH, Khor KA, Xia ZT. A complete polarization model of a solid oxide fuel cell and its sensitivity to the change of cell component thickness. J Power Sources. 2001;93:130-40.

[28] Ni M. 2D heat and mass transfer modeling of methane steam reforming for hydrogen production in a compact reformer. Energy Conversion and Management. 2013;65:155-63.

[29] Luo Y, Shi Y, Li W, Cai N. Comprehensive modeling of tubular solid oxide electrolysis cell for co-electrolysis of steam and carbon dioxide. Energy. 2014;70:420-34. 


\section{List of Tables}

Table 1 Material thermodynamic properties

Table 2 Model tuning parameters

Table 3 Operation parameters for operating potential effect study in DC-SOFC

Table 4 Operation parameters for cathode inlet gas temperature effect study in DC-SOFC

Table 5 Operation parameters for $D_{c e}$ effect study in DC-SOFC 
Table.1 Material thermodynamic properties[28, 29]

\begin{tabular}{|c|c|c|}
\hline Parameters & Value & Unit \\
\hline \multicolumn{3}{|c|}{ Thermal conductivity } \\
\hline Carbon & 1.59 & $\mathrm{~W} \mathrm{~m}{ }^{-1} \mathrm{~K}^{-1}$ \\
\hline Electrode & 13.54 & $\mathrm{~W} \mathrm{~m} \mathrm{~m}^{-1} \mathrm{~K}^{-1}$ \\
\hline Electrolyte & 2.7 & $\mathrm{~W} \mathrm{~m}{ }^{-1} \mathrm{~K}^{-1}$ \\
\hline \multicolumn{3}{|c|}{ Specific heat capacity } \\
\hline Carbon & 887.5 & $\mathrm{~J} \mathrm{~kg}^{-1} \mathrm{~K}^{-1}$ \\
\hline Electrode & 390 & $\mathrm{~J} \mathrm{~kg}^{-1} \mathrm{~K}^{-1}$ \\
\hline Electrolyte & 300 & $\mathrm{~J} \mathrm{~kg}^{-1} \mathrm{~K}^{-1}$ \\
\hline \multicolumn{3}{|l|}{ Density } \\
\hline Carbon & 1700 & $\mathrm{~kg} \mathrm{~m}^{-3}$ \\
\hline Electrode & 6870 & $\mathrm{~kg} \mathrm{~m}^{-3}$ \\
\hline Electrolyte & 2000 & $\mathrm{~kg} \mathrm{~m}^{-3}$ \\
\hline \multicolumn{3}{|l|}{ Thickness } \\
\hline Anode & 20 & $\mu \mathrm{m}$ \\
\hline Electrolyte & 201 & $\mu \mathrm{m}$ \\
\hline Cathode & 20 & $\mu \mathrm{m}$ \\
\hline \multicolumn{3}{|l|}{ Porosity } \\
\hline Anode & 0.46 & \\
\hline Cathode & 0.46 & \\
\hline
\end{tabular}


Table. 2 Model tuning parameters

\begin{tabular}{|l|l|l|}
\hline Parameter & Value & Unit \\
\hline Cathode tortuosity & 3 & \\
\hline Anode tortuosity & 3 & \\
\hline $\mathbf{O}_{\mathbf{2}}$ exchange current density $\boldsymbol{i}_{\boldsymbol{O}_{2}}$ & 400 & $\mathrm{Am}^{-2}$ \\
\hline CO exchange current density, $\boldsymbol{i}_{\boldsymbol{C o}}$ & 450 & $\mathrm{Am}^{-2}$ \\
\hline CO charge transfer coefficient, $\boldsymbol{\alpha}_{\boldsymbol{C o}}$ & 0.5 & \\
\hline O charge transfer coefficient, $\boldsymbol{\alpha}_{\boldsymbol{o}_{2}}$ & 0.5 & \\
\hline Equilibrium constant of Boudouard & $6 \times 10^{13} \cdot \frac{T-973}{150}$ & $1 / \mathrm{s}$ \\
\hline reaction & & \\
\hline
\end{tabular}

Table. 3 Operation parameters for operating potential effect study in DC-SOFC

\begin{tabular}{|l|l|c|}
\hline Parameter & Value & Unit \\
\hline Operating potential & $0.6-1.0$ & $\mathrm{~V}$ \\
\hline Anode inlet gas flow rate & 0 & \\
\hline Cathode inlet gas flow rate & 400 & SCCM \\
\hline Cathode gas composition & Air & \\
\hline Cathode inlet gas temperature & 1073 & $\mathrm{~K}$ \\
\hline
\end{tabular}

Table. 4 Operation parameters for cathode inlet gas temperature effect study in DC-SOFC

\begin{tabular}{|l|l|c|}
\hline Parameter & Value & Unit \\
\hline
\end{tabular}




\begin{tabular}{|l|l|l|}
\hline Operating potential & $0.6-1.0$ & $\mathrm{~V}$ \\
\hline Anode inlet gas flow rate & 0 & \\
\hline Cathode inlet gas flow rate & 400 & SCCM \\
\hline Cathode gas composition & Air & \\
\hline Cathode inlet gas temperature & $1023-1173$ & $\mathrm{~K}$ \\
\hline
\end{tabular}

Table. 5 Operation parameters for $D_{c e}$ effect study in DC-SOFC

\begin{tabular}{|l|l|l|}
\hline Parameter & Value & Unit \\
\hline Operating potential & $0.6-1$ & $\mathrm{~V}$ \\
\hline Distance between anode & $59-2059$ & $\mu \mathrm{m}$ \\
\hline chamber and electrode, $\boldsymbol{D}_{\boldsymbol{c}} \boldsymbol{\text { Anode inlet gas flow rate }}$ & 0 & \\
\hline Cathode inlet gas flow rate & 400 & $\mathrm{SCCM}$ \\
\hline Cathode gas composition & Air & $\mathrm{K}$ \\
\hline Cathode inlet gas temperature & 1073 & \\
\hline
\end{tabular}




\section{List of Figures}

Fig.1. Schematic of electrolyte supported DC-SOFC(a) and model validation for DC-SOFC(b).

Fig.2 Effect of operating potential on cell current density and temperature

Fig.3. Cell temperature distribution at $1.0 \mathrm{~V}$ (left) and $0.6 \mathrm{~V}$ (right) operating potential.

Fig.4. Breakdown of heat power from different components in the cell.

Fig.5. Cathode inlet gas temperature effects on cell temperature distribution at $1.0 \mathrm{~V}$

Fig.6. Cathode inlet gas temperature effects on cell temperature distribution at $0.6 \mathrm{~V}$ operating potential (a) and cathode $\mathrm{O} 2$ molar fraction (b) with $1123 \mathrm{~K}$ inlet gas temperature.

Fig.7 Effects of Dce on the temperature distribution in the cell with $1073 \mathrm{~K}$ cathode inlet gas temperature and $0.7 \mathrm{~V}$ operating potential

Fig.8 Effects of Dce on the CO molar fraction distribution in the anode with 1073K cathode inlet gas temperature and $0.7 \mathrm{~V}$ operating potential 

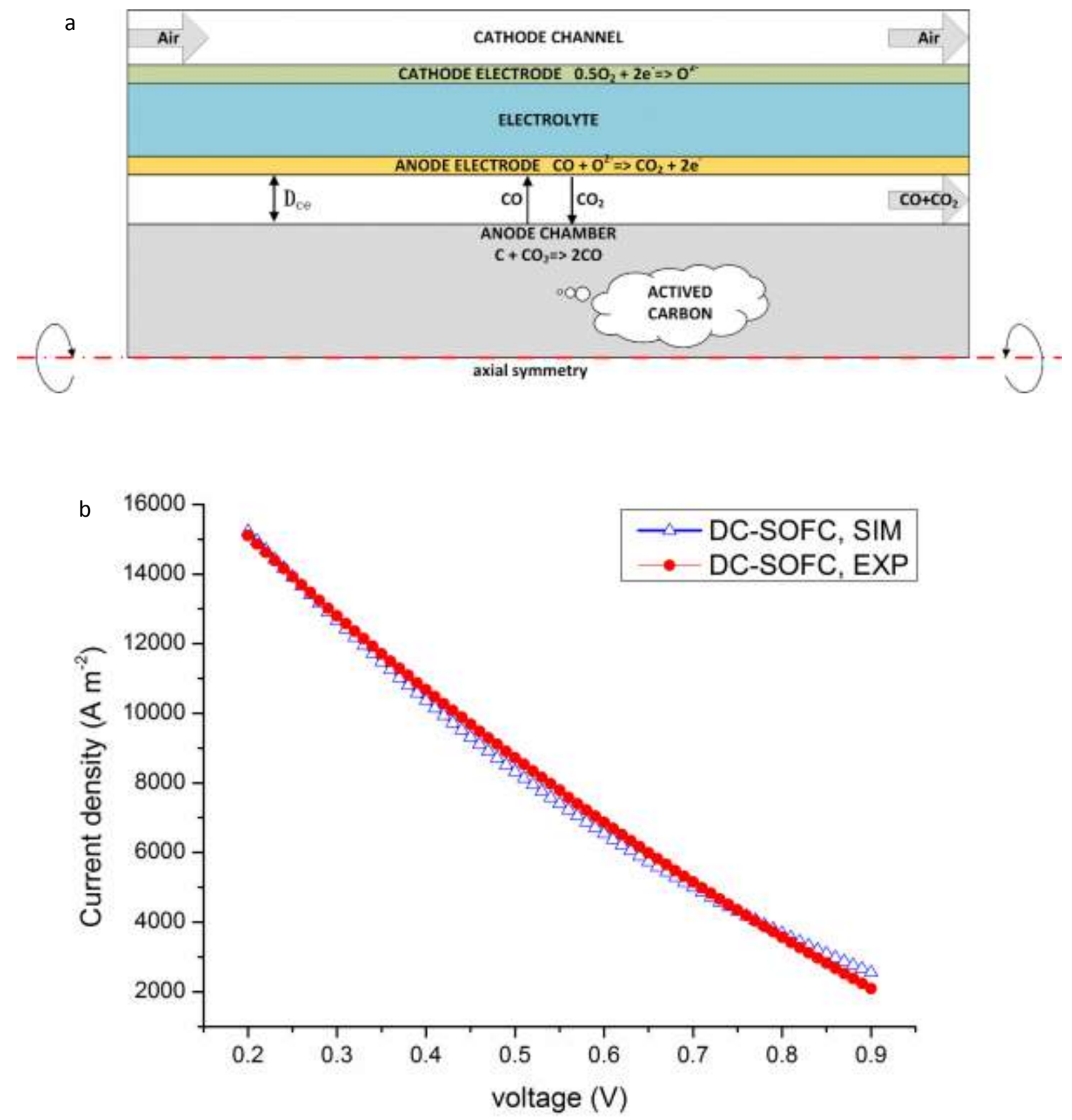

Fig.1. Schematic of the electrolyte supported DC-SOFC(a) and model validation for DC-SOFC. 


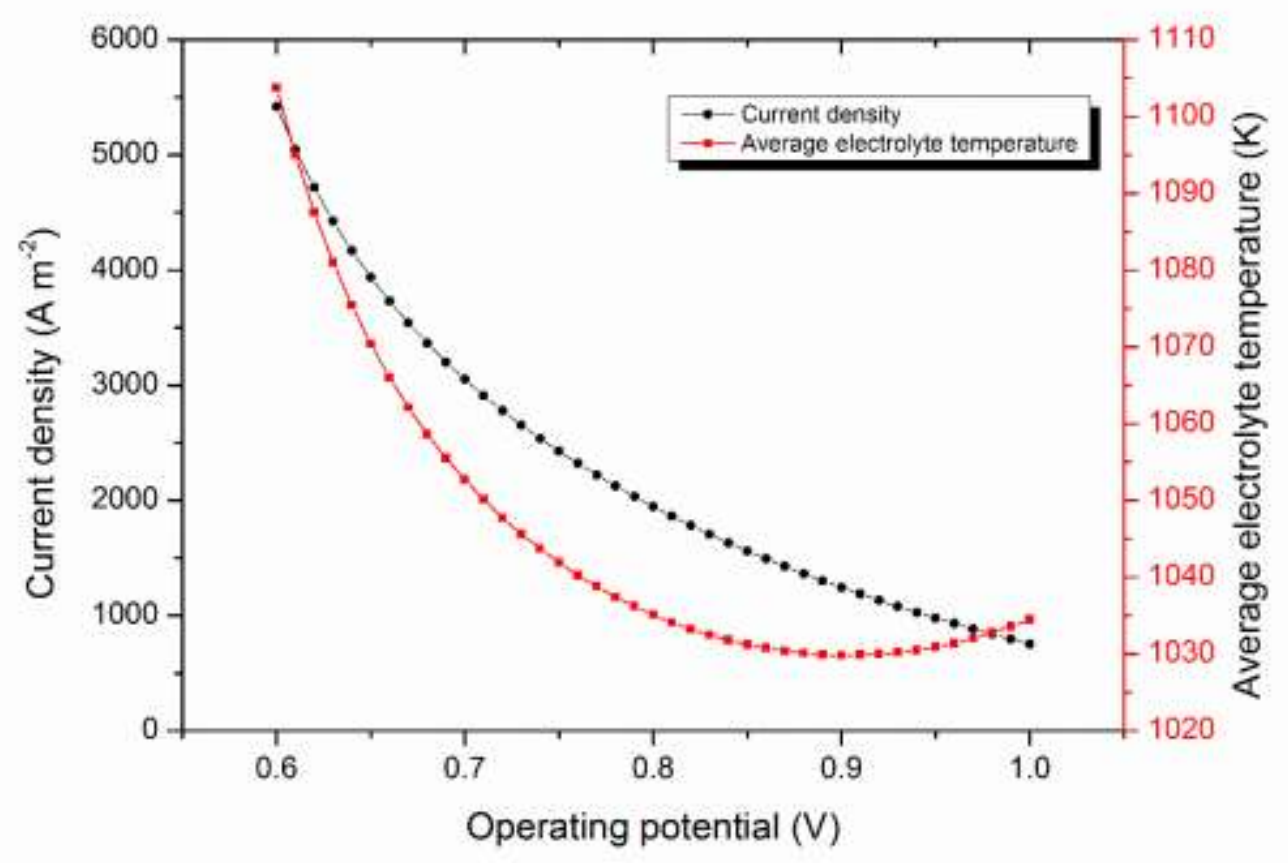

Fig. 2. Effect of operating potential on cell current density and temperature

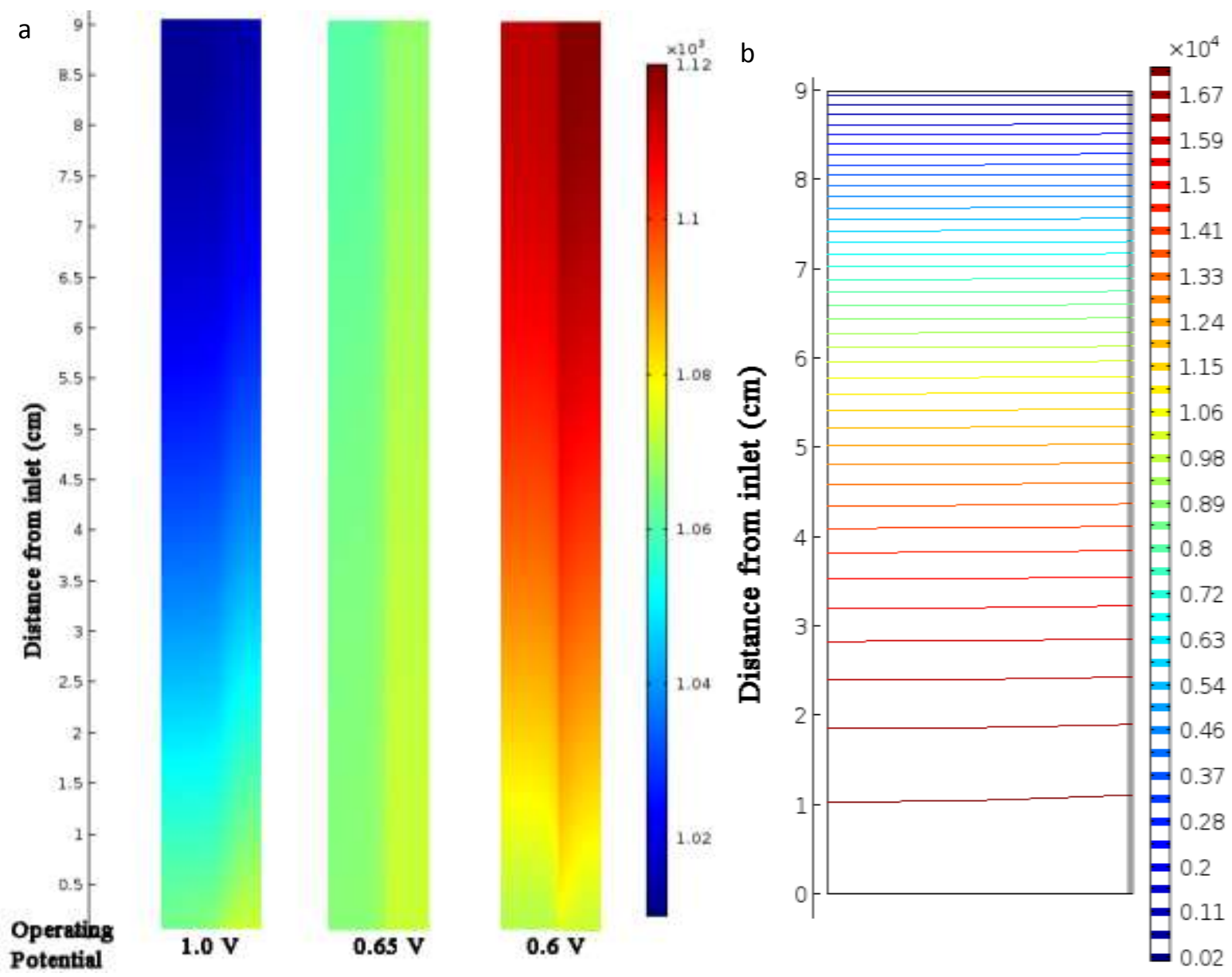

Fig. 3. Cell temperature distribution at $1.0 \mathrm{~V}, 0.65 \mathrm{~V}$ and $0.6 \mathrm{~V}$ operating potential (a) and gauge pressure $(\mathrm{Pa})$ distribution in anode chamber at $0.6 \mathrm{~V}$ operating potential (b). 

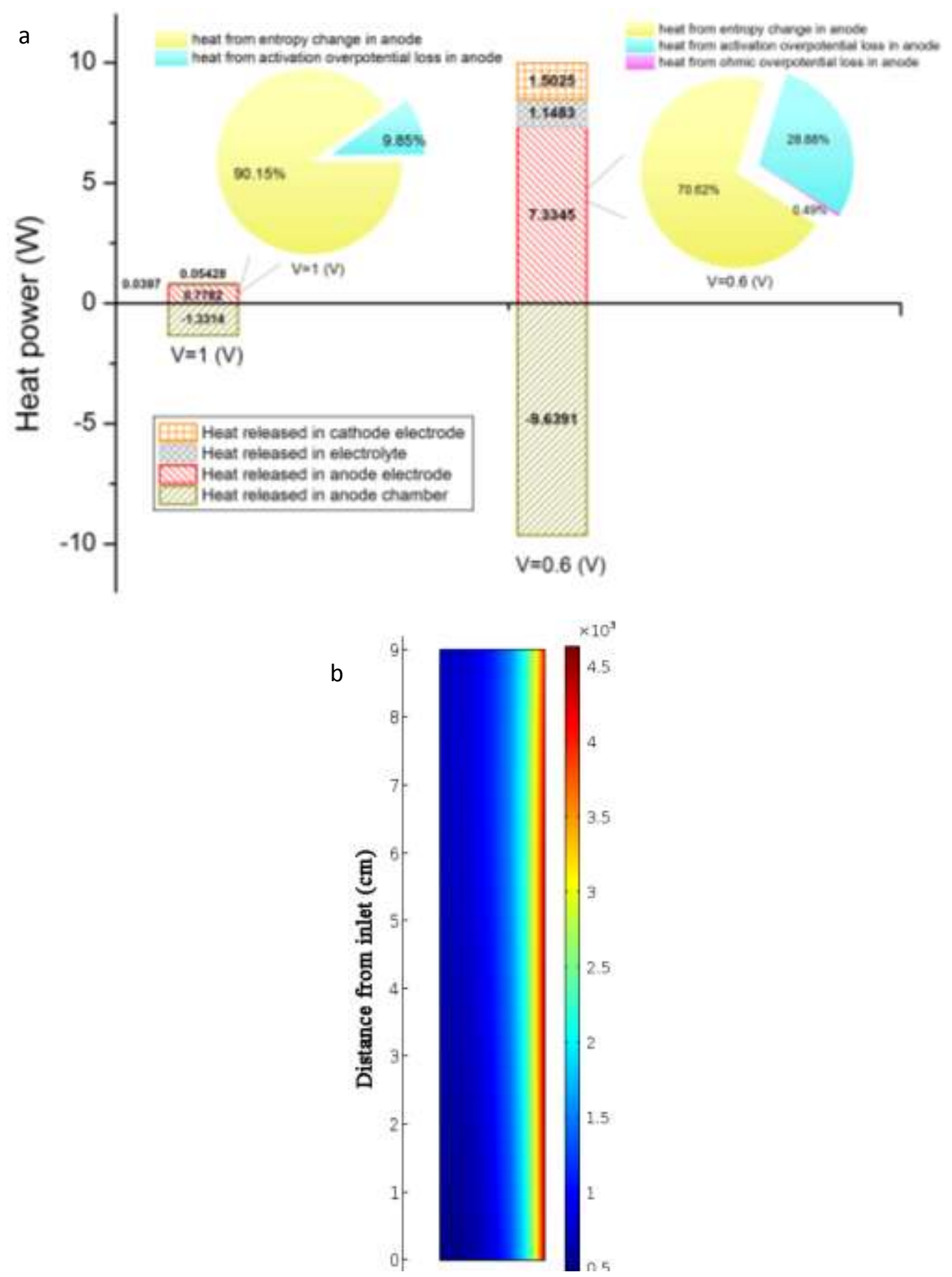

Fig. 4. Breakdown of heat power from different components in the cell (a) and anode electrochemical reaction rate $\left(\mathrm{mol} \cdot \mathrm{m}^{-3} \cdot \mathrm{s}^{-1}\right)(\mathrm{b})$. 


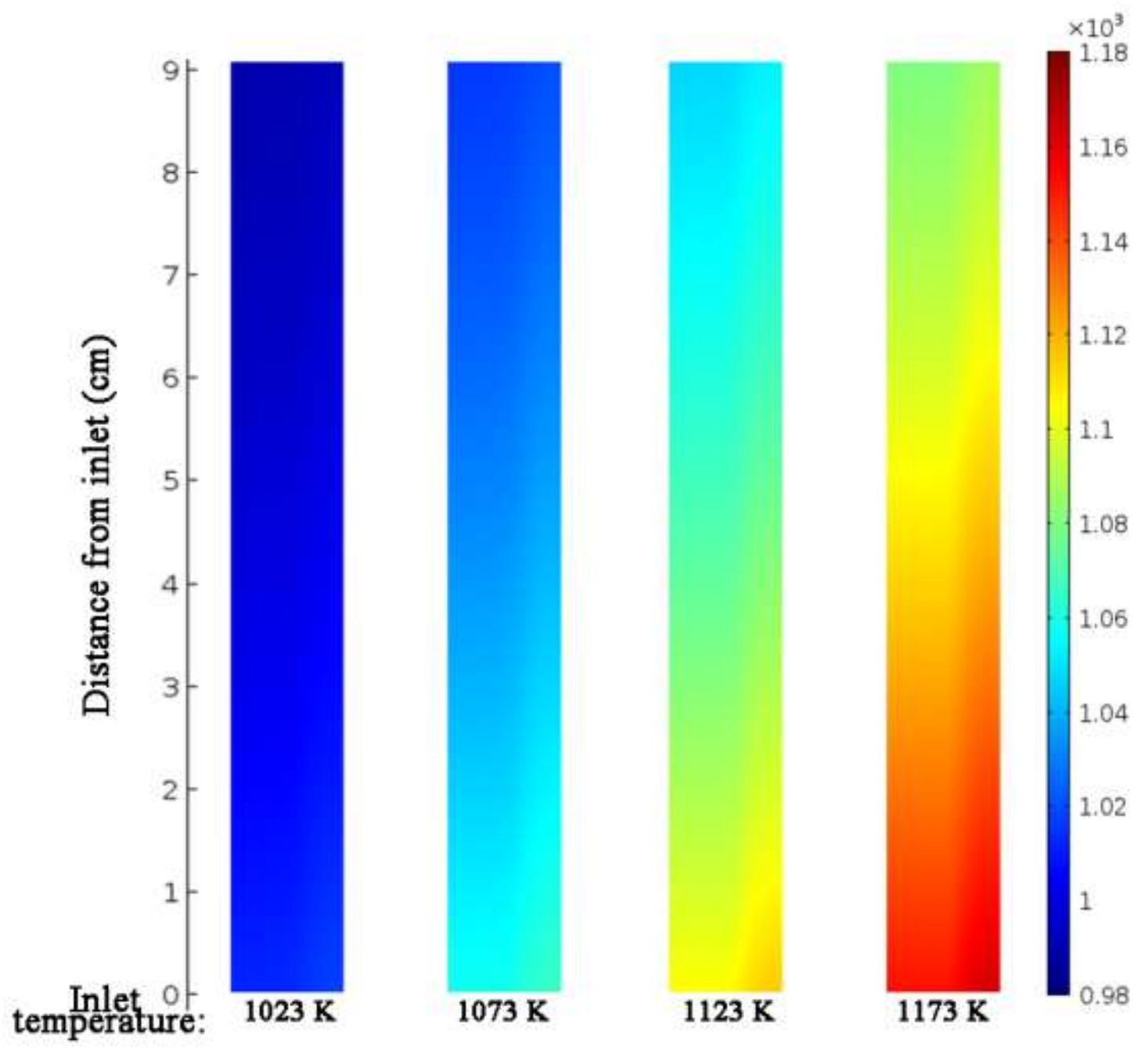

Fig. 5. Cathode inlet gas temperature effects on cell temperature distribution at $1.0 \mathrm{~V}$ 


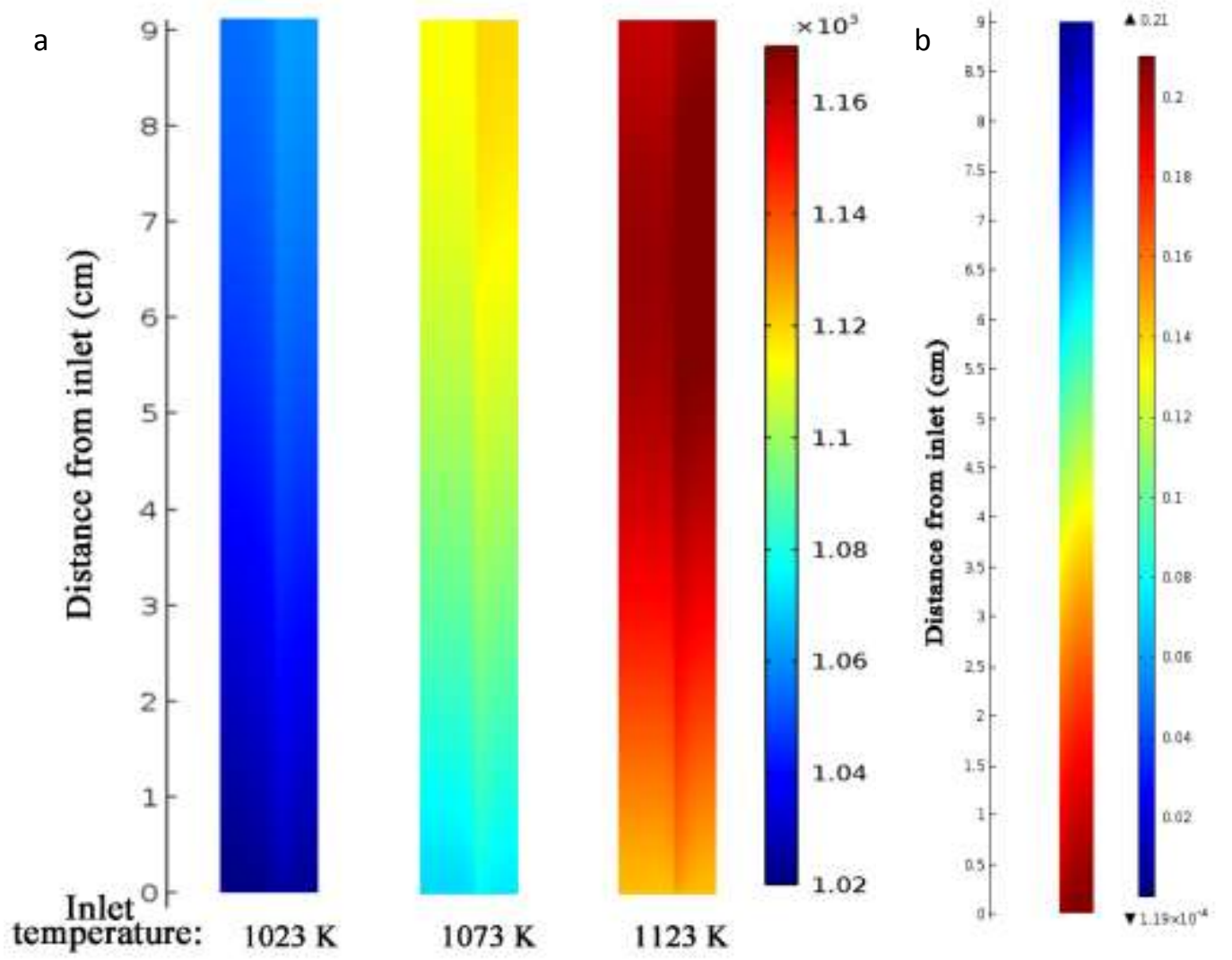

Fig. 6. Cathode inlet gas temperature effects on cell temperature distribution at $0.6 \mathrm{~V}$ operating potential (a) and cathode $\mathrm{O}_{2}$ molar fraction (b) with $1123 \mathrm{~K}$ inlet gas temperature. 

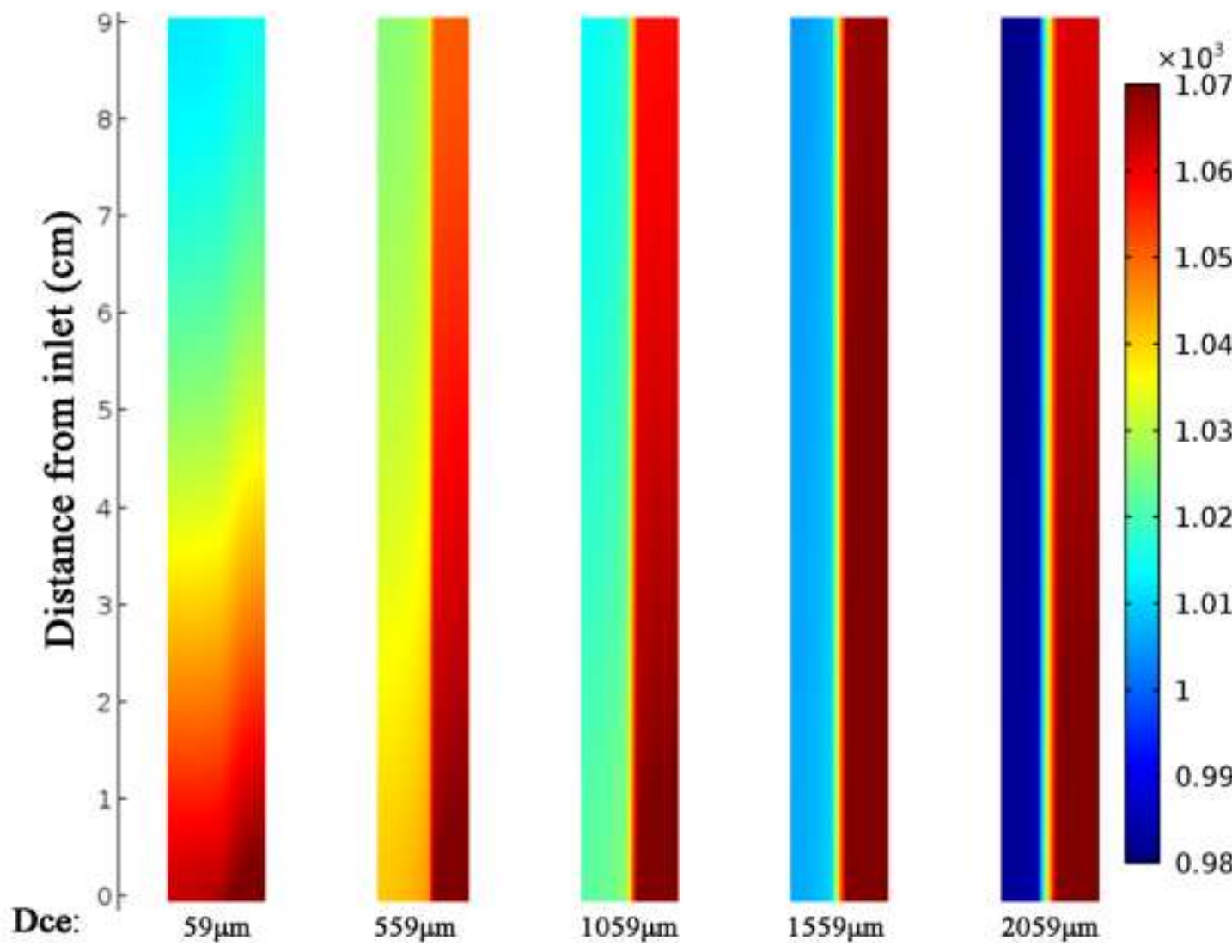

Fig. 7. Effects of Dce on the temperature distribution in the cell with $1073 \mathrm{~K}$ cathode inlet gas temperature and $0.7 \mathrm{~V}$ operating potential 


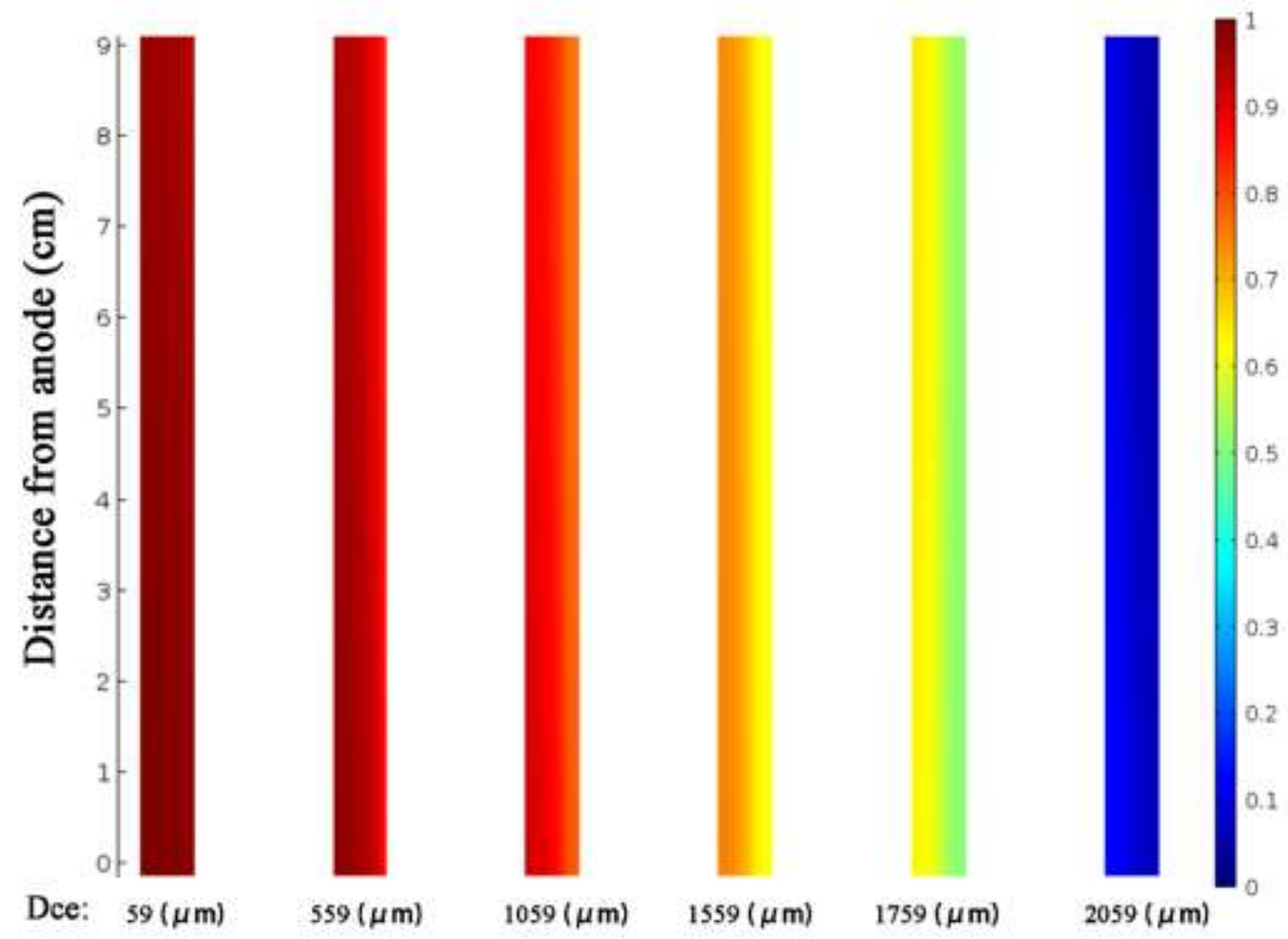

Fig. 8. Effects of Dce on the CO molar fraction distribution in the anode with $1073 \mathrm{~K}$ cathode inlet gas temperature and $0.7 \mathrm{~V}$ operating potential 